\title{
Study on Prevalence of Small Ruminants Lungworm in Asella Municipal Abattoir, Arsi Zone, South East Ethiopia
}

\author{
Kemer Kadi $^{\alpha}$, Dereje Baye ${ }^{\sigma}$, Hubad Hussien $^{\rho}$, Mukarim Abdurahaman ${ }^{\beta}$ \\ ${ }^{\alpha, \rho, \beta}$ Jimma University, College of Agriculture and Veterinary Medicine (JUCAVM). \\ ${ }^{\rho}$ Chole wereda Livestock and fisheries resource development office.
}

\begin{abstract}
A cross-sectional study was conducted from November 2014 to March 2015 in Asella municipal Abattoir, south east Ethiopia, with the objectives to determine the prevalence, identifying the species of lungworms involved and assesses possible risk factors of lungworms in small ruminants. For this purpose, lungs and fecal samples were collected by using simple random method from a total of 384 small ruminants were examined for the presence of lungworms. The overall prevalence of lung worm infection in the study was $51.0 \%$ and $53.1 \%$ in coprological examinations were found by Modified Baeremannes technique and postmortem findings, respectively. The specific prevalence of lungworms in the study area was $31.2 \%$ in goats and $57.4 \%$ in sheep. Animal species, sex, body condition and age were identified as risk factors for the occurrence of lungworms. Statistically significant $(P<0.05)$ difference was noticed in the prevalence of lungworms between species of animals. However, there were no statistically significant difference in the prevalence of lungworms was observed among different body condition, age and sexes of study animals $(p>0.05)$.The prevalence of species of lungworm identified were Muellerius capillaris (19.3), Dictyocaulus filaria (18.2\%), protostrongylus refuscens and mixed infection (9.4\%) were identified during this study. In conclusion, due to its impact on production and health of small ruminants, emphasis should be given for the control and prevention of lungworm infection in this area.
\end{abstract}

Keywords: Abattoir, Asella, Lungworm Infection, Small ruminant

\section{INTRODUCTION}

Helminthes parasites of small ruminants are ubiquitous, with many tropical and sub-tropical environments of the world; providing nearly perfect conditions for their survival and development (Hansen and Perry, 1994). Helminthiasis of small ruminants is one of considerable parasitic diseases which have significance in a wide range of agro-climatic zones in Sub-Saharan Africa and constitute one of the most important constraints to small ruminant production (ILCA, 1990). The production loss is a direct result of clinical and subclinical helminthes infections resulting in low productivity due to stunted growth, insufficient weight gain, poor feed utilization and mortality and indirect losses associated with treatment and control costs (Ayalew et al., 2011).

In the highland areas, infection with lungworm parasites is the common cause of high mortality and morbidity insheeppopulation (FAO, 2002). Lungworms are parasitic nematodes known for infection of the lower respiratory tract, characterized by respiratory distress, trachitis, bronchitis and pneumonia (Kimberling, 1988). The common lungworms in sheep are: Dictyocaulusfilaria, Muellerius capillaries, and Protostrongylus rufescens (Radostits et al., 2007). These nematodes belong to two super families, Trichostrogyloidae (D. filaria) and Metastrongyloidae ( $P$. rufescens and $M$. capillaries) (Urquhart et al., 1996; Radostits et al., 2007). Trichostrogyloidae and certain Metastrongyloidae are known to exist in East Africa (Ethiopia, Kenya and Tanzania) and South Africa (Torncy, 1989). Endo - parasites, including D. filaria, are major cause of death and morbidity in the Ethiopian highlands; and up to half of all sheep deaths and morbidity on farms in Ethiopia highlands are caused by pneumonia and endo - parasites (ILCA, 1990).

Primary finding on prevalence of lungworm infection of small ruminants in different parts of Ethiopia (Sefinew et al., 1999; Paulos, 2000; Alemu et al., 2006 ; Dawit, and Abdu, 2011; Regassa et al., 
2009; Mekonnen et al., 2010;Serkalem et al.,2012; Fentahun et al.,2012;Terefe et al., 2012), in Wollo, Chilalo, Northern Ethiopia, Jimma town, Dessie and Kombolcha districts, Gondar Town, Dale District, Jimma and Gondar respectively; with prevalence of $71.30 \%, 52.54 \%, 53.60 \%$, $26.00 \%, 36.90 \%, 33.83 \%, 60.80 \%, 25.24 \%$, and $46.00 \%$ respectively. Many studies in different parts of the country show that lung worm infection in small ruminant is prevalent and causes high economic loss however, the prevalence of the disease in different species of small ruminants has not been well quantified and compared in Asella municipal abattoir Arsi Zone of Oromia Regional State, south east of Ethiopia. So the present study was planned to determine the current prevalence of lungworm infection in different species of small ruminants through coproscopic and postmortem examination, identify the species of lungworms involved in small ruminants in study area and to study the association of different risk factors.

\section{Materials AND Methods}

\subsection{Description of the Study Area}

The study was conducted from October 2014 to March 2015 in Asella town, at Asella municipal abattoir. Asella town is located in Arsi Zone of Oromia Regional State, South Eastern part of Ethiopia at about $175 \mathrm{kmsaway}$ from the capital Addis Ababa. Asella town geographically located at an elevation of 1650-3000 meters above sea level (m.a.s.l). The area has highland escarpment, midland and lowland climatic zones. About $37 \%$ of the total area is highland $(>2400 \mathrm{~m}), 52 \%$ midland $(1800-2400 \mathrm{~m})$ and $11 \%$ is lowland $(<1800 \mathrm{~m})$ with in $6^{\circ} 59^{\prime}$ and $8^{0} 49^{\prime}$ latitude and $40^{\circ} 44^{\prime}$ East longitude while the climatic condition of the area is "Weynadega".

The area receives an annual range of rain fall from 700-1658 $\mathrm{mm}$ and annual average humidity ranging from 43-60\%. The area has a biomodal rainfall occurring from March to April (a short rainy season) and from July to October (long rainy season). The annual temperature range is $10-22.6^{\circ} \mathrm{c}$. It has a daily maximum temperature that can reach up to $28^{\circ} \mathrm{c}$ and minimum temperature of $10^{\circ} \mathrm{c}$. The area is known to have three different soil types: black soil, clay soil and sandy soil. Asella town and the surrounding farming community, has a total area of 300.21 sq.km. This, about $208.43 \mathrm{sq} . \mathrm{km}$ $(69.4 \%)$ of the total area is agricultural land, 40.61sq.km (13.5\%) pastoral land, 6.74sq.km (2.3\%) forest, 39.34sq.km (13.5\%) land for construction and 5.08sq.km (1.69\%) non-fertile land (TWRAD,2008).

Livestock estimate of the year 2010/11 given by the agricultural bureau of Tiyo woreda indicates that the woreda has 50347 bovines, 16964 equines, 19453 ovine, 6884 caprine, and 22485 poultry (CSA, 2013).

\subsection{Study Population}

The study animals were small ruminants slaughtered at Asella municipal abattoir during study period. Indigenous sheep and goat breeds of mixed age groups, sexes and various bodies Conditions brought from different location of south east Arsi zone were used as study population.

\subsection{Study Design}

Cross sectional study was conducted from November 2014 to March 2015 G. C. in Asella municipal abattoir, south east, Ethiopia.

The total of 384 small ruminants were examined coprologically and their lungs were examined by postmortem examination for the presence of larvae of lung worms in their feces and adult lung worms in trachea and bronchi of lungs respectively. Out of the total 384 small ruminants, 291 were sheep and the rest 93 were goats. The number of sheep and goats which were included in my study was determined by their proportion to the total number of small ruminants those were slaughtered at municipal abattoir during my study period based on the previously recorded data.

In this study, sampled animals were grouped into different sex, age and body condition groups. Sampled animals were grouped into two different age groups, namely small ruminants having ages of less than or equal to one year ( $\leq 1$ year) were considered as young, where as small ruminants having ages of greater than one year (> 1year) were considered as adult. Study animals were also grouped into three groups based on their body conditions, namely small ruminants having poor, medium and good body conditions. Risk factors like animal species, sex, age and body conditions were considered in the study. 


\subsection{Sampling}

\subsubsection{Sample Size Determination}

The sample size required for this study was determined depending on the expected prevalence of the parasite and the desired absolute precision. The sample size was computed using the formula given in Thrusfield (2005) as follows.

$$
\mathrm{N}=\frac{1.96^{2} \times \operatorname{Pexp}(1-\operatorname{Pexp})}{\mathrm{d}^{2}}
$$

Where: $\mathrm{N}=$ required sample size; Pexp = expected prevalence; $\mathrm{d}=$ desired absolute precision

There was no previous study on prevalence of lung worm infection in small ruminants in Asella municipal abattoir, southeast, Ethiopia. Therefore, an expected prevalence of $50 \%$ was used to estimate the sample size. Using desired $95 \%$ confidence level, $5 \%$ precision, the numbers of sheep and goats needed to determine the prevalence of lung worm infection in small ruminants were 384 .

\subsubsection{Sampling Method}

Simple random sampling technique was used to select study animals from those which were slaughtered at Asella municipal abattoir during the study period.

\subsection{Sample Collection and Transportation}

Sample collection was carried out in all selected animals in abattoir. For coprological examination, faecal samples were collected directly from the rectum of animals after wearing of plastic disposable glove. The fecal samples were put into screw capped glass bottles and were properly packed. All fecal samples were clearly labeled with the date of sampling, type of sample and the identification number of the animal (Radostits et al., 2007); then the fecal samples were transported in ice box to Asella Regional Veterinary Laboratory for identification of the larvae (L1) of lung worms.

\subsection{Identification of Lung Worms}

In the laboratory, isolation of lung worms from feces of small ruminants was performed by using modified Baerman technique. Fresh feces were weighed and wrapped with gauze, fixed onto a string in a beaker filled with warm water; and then the apparatus was left for 24 hours. Finally if the feces of animals contain lung worms, the larvae migrate to the gauze and settle at the bottom of the glass. After siphoning off the supernatant, the sediment was examined under microscope with low power of magnificationto identify the species of lung worms (Charles, 2006).

Identification of the larvae of the parasite was done by their difference in morphological features of larvae (L1) under microscope (Dunn, 1998). The larvae (L1) of Dictyocaulus filariais differentiated from the other two lungworms by having characteristic cuticular knob at anterior extremity, large size and blunt tail and intestinal inclusions on larvae (L1) (Dunn, 1998). While the larvae of Protostrongylus rufescens and Muellerius capillaries were differentiated by their characteristic features at the tip of their tails (Geoffrey, 1992).The L1 of P. rufescens and M. capillaris have small size, absence of anterior cuticular knob; additionally L1 of $M$. capillaris possesses dorsal spine at pointed wave tail, but $\mathrm{L}_{1}$ of $P$. rufescens has no dorsal spine (Geoffrey, 1992).

In the postmortem examination, lungs were palpated for the presence of nodules to identify adult lung worms. In the presence of the nodules, they were trimmed off and worms were extracted from the tissue by gentle compression of a small non-calcified nodules or part of large nodules between two glass slides and then the adult lung worm was drawn away from lung tissues with a thumb forceps. To collect all worms, the nodules were soaked in a beaker containing water. The collected worms were then identified and recorded as stated in Radostits et al. (2007). Air passages were opened starting from the trachea down to the small bronchi with fine blunt pointed scissor to detect the presence of adult lung worm parasites. Finally, the adult parasites were identified by their morphological difference as stated in Radostits et al. (2007).

\subsection{Data Management and Analysis}

The data were entered and managed in Microsoft Excel work sheet. All the data analysis was done by Statistical Package for Social Science (SPSS) software version 20. Descriptive statics such as percentages and frequency distribution were used to describe the nature and the characteristics of the 
data. The prevalence of lungworm infection was analyzed using percentages. The association of different risk factors with the prevalence of the parasites was computed by Chi - square $\left(\chi^{2}\right)$ test. For all analysis, a P-value less than $0.05(5 \%)$ at $95 \%$ confidence level were considered as statistically significant.

\section{RESUlTS}

\subsection{Prevalence of Lung Worm Infection in Small Ruminants}

The current prevalence of lung worm infection of small ruminants in study area was determined by coprological investigation of fecal samples for the presence of larvae (L1) and by post mortem investigation of lungs for the presence of adult parasites of lung worms.

i. Prevalence of Lung Worm Infection in Small Ruminants by Coprological Examination of Fecal Samples

Out of 384 small ruminants (291 sheep and 93 goats) sampled $51.10 \%(196 / 384)$ of animals were found to be infected with one or more larvae (L1) of lung worms when their fecal samples were examined coprologically. However, the prevalence of lung worm infection was different with species of animals. It was $31.20 \%$ (29/93) and $57.40 \%$ (167/291) in goats and in sheep respectively as shown in table 3 below.

Table3. Prevalence of lungworm infection in different species of small ruminantin the study area

\begin{tabular}{|l|l|l|l|l|}
\hline Species of animals & No of samples & № of infected animals & Prevalence (\%) & 95\% of CI \\
\hline Ovine & 291 & 167 & 57.40 & $46.25-68.51$ \\
\hline Caprine & 93 & 29 & 31.20 & $21.80-40.60$ \\
\hline Total & $\mathbf{3 8 4}$ & $\mathbf{1 9 6}$ & $\mathbf{5 1 . 1 0}$ & $\mathbf{4 3 . 8 0}-\mathbf{5 8 . 4 0}$ \\
\hline
\end{tabular}

The major species of lung worms of small ruminants those were identified coprologically in the study area were Muellerius capillaris, Dictyocaulus filaria and Protostrongylus rufescens. Coprologically, the larvae (L1) of two and more species of lung worms were identified from fecal samples of some small ruminants; and it was found that mixed infection with two or more species of lung worms might be occurred in small ruminants.

The prevalence of different species of lung worms those were identified cooprologically was found to be different among positive fecal samples of small ruminants; and it was found that

19. $30 \%$ (74/384), $18.20 \%$ (70/384), $4.2 \%(16 / 384)$ and $9.4 \%(36 / 384)$ of animals were infected byMuellerius capillaris, Dictyocaulus filaria, Protostrongylus rufescens and by mixed infection of two or more species of lung worms respectively as shown in table 4 below.

Table4. Prevalence of different species of lung worms of small ruminants in the study area

\begin{tabular}{|l|l|l|l|}
\hline $\begin{array}{l}\text { Identified species of lung } \\
\text { worms }\end{array}$ & $\begin{array}{l}\text { No of positives from the total sampled } \\
\text { animals }(\mathrm{n}=384)\end{array}$ & Prevalence (\%) & 95\% of CI \\
\hline Muellerius capillaris & 74 & 19.30 & $15.35-23.25$ \\
\hline Dictyocaulus filaria & 70 & 18.20 & $14.40-22.00$ \\
\hline Protostrongylus rufescens & 16 & 4.20 & $2.20-6.20$ \\
\hline Mixed infection & 36 & 9.40 & $6.50-12.30$ \\
\hline Total & $\mathbf{1 9 6}$ & $\mathbf{5 1 . 1 0}$ & $\mathbf{4 3 . 8 0}-\mathbf{5 8 . 4 0}$ \\
\hline
\end{tabular}

ii. Prevalence of Adult Lung Worm Infection in Small Ruminants by Postmortem Examination of Lungs

Out of the total 384 slaughtered small ruminants (291 sheep and 93 goats) in Asella municipal abattoir during study period, their lungs were examined for the presence of adult lung worms; and it was found that $53.10 \%(204 / 384)$ lungs were infected by different species of lungworms. However, the prevalence of adult lung worm infection was found to be different in two species of small ruminants; and it was $60.10 \%(175 / 291)$ and $31.20 \%$ (29/93) in sheep and in goats respectively as shown in table 5 below. 
Study on Prevalence of Small Ruminants Lungworm in Asella Municipal Abattoir, Arsi Zone, South East Ethiopia

Table5. Prevalence of adult lungworm infection in different species of small ruminants by post mortem examination of lungs in the study area

\begin{tabular}{|l|l|l|l|l|}
\hline Species of animals & No of samples & No of infected animals & Prevalence $(\%)$ & $95 \%$ of CI \\
\hline Ovine & 291 & 175 & 60.10 & $54.50-65.70$ \\
\hline Caprine & 93 & 29 & 31.20 & $21.80-40.60$ \\
\hline Total & $\mathbf{3 8 4}$ & $\mathbf{2 0 4}$ & $\mathbf{5 3 . 1 0}$ & $\mathbf{4 8 . 1 0}-\mathbf{5 8 . 1 0}$ \\
\hline
\end{tabular}

\subsection{Comparison of the Current Prevalence of Lung Worm Infection in Small Ruminants Determined by Coprological Examination and Post Mortem Examination}

The overall prevalence of lung worm infection in small ruminants that was determined by identifying the larvae (L1) of lung worms from fecal samples using coprological examination was compared with the overall prevalence of lung worm infection in small ruminants which was determined by post mortem examination of lungs for the presence of adult parasites in the lungs. It was found that the overall prevalence of lung worm infection that was determined by the two methods was almost similar and it was $51.10 \%$ and $53.10 \%$ in coprological examination of fecal samples and in post mortem diagnosis of lungs respectively as shown in table 6 below.

Table6. Prevalence of lung worm infection in small ruminants determined by coprological and post mortem examination in the study area

\begin{tabular}{|l|l|l|l|l|}
\hline Method used & No of animals examined & No of positives & Prevalence $(\%)$ & 95 \% of CI \\
\hline Coprology & 384 & 196 & 51.10 & $43.80-58.40$ \\
\hline Post mortem & 384 & 204 & 53.10 & $48.10-58.10$ \\
\hline
\end{tabular}

\subsection{Association between Prevalence of Lung Worm Infection with Different Risk Factors}

\subsubsection{Association between Prevalence of Lung Worm Infection Determined by Coprological Examination with Different Risk Factors}

Further the association of the prevalence of lung worm infection in small ruminants with different risk factorswas assessed. Coprological examination showed that the overall prevalence of lung worm infection caused by different species of lung worms was different in two species of animals, and the prevalence was $60.10 \%$ and $31.20 \%$ in sheep and goats respectively. The difference was statistically significant $\left(\chi^{2}=26.18, \mathrm{P}<0.05\right)$ as shown in table 7 below.

Table7. Association of the prevalence of lung worm infection in small ruminants with species of animals

\begin{tabular}{|l|l|l|l|l|l|l|}
\hline $\begin{array}{l}\text { Species of } \\
\text { animals }\end{array}$ & $\begin{array}{l}\text { Total No of examined } \\
\text { animals }\end{array}$ & No of positives & $\begin{array}{l}\text { Prevalence } \\
(\%)\end{array}$ & $95 \%$ CI & $\chi^{2}$ & P - value \\
\hline & & & & & & \\
\hline Ovine & 291 & 175 & 60.10 & $54.50-65.70$ & 26.18 & 0.00 \\
\hline Caprine & 93 & 29 & 31.20 & $21.80-40.60$ & & \\
\hline Total & $\mathbf{3 8 4}$ & $\mathbf{2 0 4}$ & $\mathbf{5 3 . 1 0}$ & $\mathbf{4 8 . 1 0}-\mathbf{5 8 . 1 0}$ & & \\
\hline
\end{tabular}

The overall prevalence of lung worm infection in small ruminants was found to be different in different age, sex and body condition categories of animals. It was also found that the prevalence of different species of lung worms was found to be different in different sex, age and body condition categories of animals.

The overall prevalence of lung worm infection in relation to sex of animals was found to be $45.45 \%$ (35/77) and 52.44\% (161/307) in male and female groups of animals respectively. The prevalence of different species of lung worms was also different in different sex groups of animals; and from the total positive animals in coprological examination of fecal samples; $71.42 \%(25 / 35), 40.00 \%(14 / 35)$, $17.14 \%(6 / 35)$ and $20.00 \%(7 / 35)$ were infected by Dictyocaulus filaria, Muellerius capillaris, Protostrongylus rufescens and by mixed infection respectively in male category of animals; and $55.27 \%$ (89/ 161), 59.00\% (95/ 161), 11.80\%(19/161) and 18.01(29/161) were infected by Dictyocaulus filaria, Muellerius capillaris, Protostrongylus rufescens and by mixed infection respectively in female category of animals as shown in table 8 below. 
Kemer Kadi et al.

Table8. Prevalence of different species of lungworm infection in relation to sex animals

\begin{tabular}{|l|l|l|l|l|l|l|l|}
\hline Sex & $\begin{array}{l}\text { No of } \\
\text { Examined }\end{array}$ & $\begin{array}{l}\text { No of } \\
\text { Positive }\end{array}$ & $\begin{array}{l}\text { Prevalence } \\
(\%)\end{array}$ & \multicolumn{3}{l|}{ Prevalence of different species of lungworm } \\
\hline & & & & D. filaria $(\%)$ & M. capillaris $(\%)$ & $\begin{array}{l}\text { P. rufescens } \\
(\%)\end{array}$ & $\begin{array}{l}\text { Mixed infection } \\
(\%)\end{array}$ \\
\hline Male & 77 & 35 & 45.50 & $25(71.42)$ & $14(40.00)$ & $6(17.14)$ & $7(20.00)$ \\
\hline Female & 307 & 161 & 52.40 & $89(55.27)$ & $95(59.00)$ & $19(11.8)$ & $29(18.0)$ \\
\hline Total & $\mathbf{3 8 4}$ & $\mathbf{1 9 6}$ & $\mathbf{5 1 . 0 0}$ & $\mathbf{1 1 4}(\mathbf{5 8 . 2 2})$ & $\mathbf{1 0 9}(\mathbf{5 5 . 6})$ & $\mathbf{2 5}(\mathbf{1 2 . 8})$ & $\mathbf{3 6}(\mathbf{1 8 . 4})$ \\
\hline
\end{tabular}

The overall prevalence of lung worm infection in relation to different age groups of animals was found to be $47.82 \%(22 / 46), 51.47 \%(174 / 338)$ in young $(\leq 1$ year) and in adult ( $>1$ year) animal respectively. It was found that the prevalence of different species of lung worms was also different in different age groups of animals; and from the total positive animals in coprological examination of fecal samples; $50.00 \%$ (11/22), $22.72 \%(5 / 22), 13.63 \%(3 / 22)$ and $13.63 \%(3 / 22)$ were infected by Dictyocaulus filaria, Muellerius capillaris, Protostrongylus rufescens and by mixed infection respectively in young animals; and $33.90 \%$ (59/174), 39. $65 \%$ (69/174), $7.47 \%$ (13/174) and 18.96 $\%(33 / 174)$ were infected by Dictyocaulus filaria, Muellerius capillaris, Protostrongylus rufescens and by mixed infection respectively in adult animals as shown in table 9 below.

Table9. Prevalence of different species of lungworm infection in relation to age of animals

\begin{tabular}{|l|l|l|l|l|l|l|l|}
\hline Age & $\begin{array}{l}\text { No of } \\
\text { examined }\end{array}$ & $\begin{array}{l}\text { No of } \\
\text { positive }\end{array}$ & $\begin{array}{l}\text { Prevalence } \\
(\%)\end{array}$ & \multicolumn{3}{l|}{ Prevalence of different species of lungworm } \\
\hline & & & & D. filaria $(\%)$ & M. capillaris $(\%)$ & P. rufescens $(\%)$ & $\begin{array}{l}\text { Mixed } \\
\text { infection }(\%)\end{array}$ \\
\hline$\leq 1$ year & 46 & 22 & 47.80 & $11(50.00)$ & $5(22.72)$ & $3(13.63)$ & $3(13.63)$ \\
\hline$>1$ year & 338 & 174 & 51.50 & $59(33.90)$ & $69(39.67)$ & $13(7.47)$ & $33(18.96)$ \\
\hline Total & $\mathbf{3 8 4}$ & $\mathbf{1 9 6}$ & $\mathbf{5 1 . 0 0}$ & $\mathbf{7 0}(\mathbf{3 5 . 7 0})$ & $\mathbf{7 4 ( 3 7 . 8 0 )}$ & $\mathbf{1 6}(\mathbf{8 . 2 0})$ & $\mathbf{3 6}(\mathbf{1 8 . 4 0})$ \\
\hline
\end{tabular}

The overall prevalence of lung worm infection in relation to different body condition categories of animals was found to $41.70 \%(5 / 12), 53.90 \%(69 / 128)$ and $50.00 \%$ ( $122 / 244)$ in poor, medium and good body condition categories of animals respectively as shown in Table 10 below. Similarly, the prevalence of different species of lung worms was also different in different body condition categories of animals; and from the total positive animals in coprological examination of fecal samples; $60.00 \%$ (3/5), $20.00 \%(1 / 5), 20.00 \%(1 / 5)$ and $0 \%$ were infected by Dictyocaulus filaria, Muellerius capillaris, Protostrongylus rufescens and by mixed infection respectively in poor body condition category of animals; and $31.88 \%$ (22/69), $42.02 \%$ (29/69), $2.89 \%(2 / 69)$ and $23.18 \%(16 / 69)$ were infected by Dictyocaulus filaria, Muellerius capillaris, Protostrongylus rufescens and by mixed infection respectively in medium body condition category of animals; and $36.88 \%$ ( 45/122), $36.10 \%$ (44/122), $10.65 \%$ (13/122) and 16. $39 \%$ (20/ 122) were infected by Dictyocaulus filaria, Muellerius capillaris, Protostrongylus rufescens and by mixed infection respectively in good body condition category of animals as shown in table 10 below.

Table10. Prevalence of lungworm infection in different body condition of study animals

\begin{tabular}{|l|l|l|l|l|l|l|l|}
\hline $\begin{array}{l}\text { Body } \\
\text { condition }\end{array}$ & $\begin{array}{l}\text { No } \\
\text { examined }\end{array}$ & $\begin{array}{l}\text { No } \\
\text { positive }\end{array}$ & $\begin{array}{l}\text { Over all } \\
\text { prevalence }(\%)\end{array}$ & \multicolumn{3}{l|}{ Prevalence of different species of lungworm } \\
\hline & & & & D. filaria (\%) & M. capillaris (\%) & P.rufescens (\%) & $\begin{array}{l}\text { Mixed } \\
\text { infection }(\%)\end{array}$ \\
\hline Poor & 12 & 5 & 41.70 & $3(60.00)$ & $1(20.00)$ & $1(20.00)$ & $0(0.00)$ \\
\hline Medium & 128 & 69 & 53.90 & $22(31.8)$ & $29(42.02)$ & $2(2.89)$ & $16(23.1)$ \\
\hline Good & 244 & 122 & 50.00 & $45(36.8)$ & $44(36.10)$ & $13(10.5)$ & $20(16.3)$ \\
\hline Total & $\mathbf{3 8 4}$ & $\mathbf{1 9 6}$ & $\mathbf{5 1 . 0}$ & $\mathbf{7 0}(\mathbf{3 5 . 7 0})$ & $\mathbf{7 4 ( 3 7 . 8 0 )}$ & $\mathbf{1 6}(\mathbf{8 . 2 0})$ & $\mathbf{3 6}(\mathbf{1 8 . 4 0})$ \\
\hline
\end{tabular}

Association of the overall prevalence of lung worm infection in small ruminants was also assessed with different risk factors like age, sex and body condition of animals. It was found that the prevalence was different with two sex categories of animals; and it was $45.50 \%$ and $52.40 \%$ in male and female sex categories of animals respectively. The difference was statistically insignificant $\left(\chi^{2}=\right.$ $12.43, \mathrm{P}>0.05)$ as shown in table 11 below. The overall prevalence of lung worm infection in small ruminants was also different with different age groups of animals; and it was $47.80 \%$ and $51.50 \%$ in young age and adult age category of animals respectively. The association of the overall prevalence of lung worm infection was statistically insignificant $\left(\chi^{2}=6.29, \mathrm{P}>0.05\right)$ as shown in table 11 below. It 
was also found that the overall prevalence of lung worm infection was different in different body condition categories of animals; and it was $41.70 \%, 53.90 \%$ and $50.00 \%$ in poor, medium and good body condition animals respectively. It was found that the association of the overall prevalence of lung worm infection was also statistically insignificant $\left(\chi^{2}=13.09\right.$; $\left.\mathrm{P}>0.05\right)$ as shown in table 11 below.

Table11. Association of the prevalence of lung worm infection in small ruminants with different risk factors

\begin{tabular}{|c|c|c|c|c|c|c|}
\hline Risk factors & No of examined & No of positives & Prevalence $(\%)$ & $95 \% \mathrm{CI}$ & $\chi^{2}$ & $\mathrm{P}$ - value \\
\hline \multicolumn{7}{|l|}{ Sex } \\
\hline Male & 77 & 35 & 45.50 & $34.39-56.61$ & \multirow[b]{2}{*}{12.43} & \multirow[b]{2}{*}{0.087} \\
\hline $\begin{array}{l}\text { Female } \\
\text { Age }\end{array}$ & 307 & 161 & 52.40 & $41.25-63.55$ & & \\
\hline Young $(\leq 1$ year $)$ & 46 & 22 & 47.80 & $33.37-62.23$ & \multirow[b]{2}{*}{6.29} & \multirow[b]{2}{*}{0.506} \\
\hline Adult(> 1 year $)$ & 338 & 174 & 51.50 & $46.18-56.82$ & & \\
\hline \multicolumn{7}{|l|}{ Body condition } \\
\hline Poor & 12 & 5 & 41.70 & $13.81-69.59$ & \multirow[b]{3}{*}{13.09} & \multirow[b]{3}{*}{0.519} \\
\hline Medium & 128 & 69 & 53.90 & $45.27-62.53$ & & \\
\hline Good & 244 & 122 & 50.00 & $\begin{array}{l}43.73-56 \\
27\end{array}$ & & \\
\hline
\end{tabular}

Coprologically, the overall prevalence of different species of lung worms was different; and it was found that out of the total positive animals $18.20 \%, 19.30 \%, 4.20 \%$ and $9.40 \%$ were infected by Dictyocaulus filaria, Muellerius capillaris, Protostrongylus rufescens and by mixed infection respectively. The association of the prevalence of different species of lung worms in total examined small ruminants was also assessed; and the difference was highly statistically significant $\left(\chi^{2}=26.18\right.$; $\mathrm{P}$ $<0.05)$ as shown in table 12 .

Table12. Association of the prevalence of different species of lungworms in total examined sheep and goats

\begin{tabular}{|l|l|l|l|l|l|l|}
\hline $\begin{array}{l}\text { Species of } \\
\text { lungworm }\end{array}$ & No examine animal & No positive & Prevalence (\%) & $\mathbf{9 5 \%} \mathbf{C I}$ & $\mathbf{X}^{2}$ & P-Value \\
\hline D. filaria & 384 & 70 & 18.20 & $14.4-22.1$ & & \\
\hline M. capillaries & 384 & 74 & 19.30 & $15.3-23.2$ & & \\
\hline P. rufescens & 384 & 16 & 4.20 & $2.2-6.2$ & 26.186 & 0.00 \\
\hline Mixed infection & 384 & 36 & 9.40 & $6.5-12.3$ & & \\
\hline Total & $\mathbf{3 8 4}$ & $\mathbf{1 9 6}$ & $\mathbf{5 1 . 0 0}$ & $\mathbf{4 6 . 0 - 5 6 . 0}$ & & \\
\hline
\end{tabular}

3.3.2. Association between Prevalence of Lung Worm Infection Determined by Post Mortem examination with Different Risk Factors

All 384 slaughtered animals (291sheep and 93goats) during study period; their lungs were examined for the presence of adult lung worm parasites. It was found that the overall prevalence of lung worm infection was found to be $53.10 \%$ (204/384). However, the specific prevalence of lung worm was different with different species of small ruminants; and it was $60.10 \%(175 / 291)$ and $31.20 \%(29 / 93)$ in sheep and in goats respectively. Association between specific prevalence of lung worm infection with two species of animals was also assessed; and it was found that it had highly statistically significant difference $\left(\chi^{2}=23.72 ; \mathrm{P}<0.05\right)$ as shown in Table 13 .

Table13. Association of prevalence of adult lung worm parasites with species of small ruminants determined by post mortem investigation of lungs

\begin{tabular}{|l|l|l|l|l|l|l|}
\hline Species & No of examined & No of positives & Prevalence (\%) & $95 \%$ CI & $\chi^{2}$ & P-value \\
\hline Sheep & 291 & 175 & 60.10 & $54.50-65.70$ & & \multirow{2}{*}{0.00} \\
\hline Goats & 93 & 29 & 31.20 & $21.80-40.60$ & 23.72 & 0.00 \\
\hline Total & $\mathbf{3 8 4}$ & $\mathbf{2 0 4}$ & $\mathbf{5 3 . 1 0}$ & $\mathbf{4 8 . 1 0}-\mathbf{5 8 . 1 0}$ & & \\
\hline
\end{tabular}

\section{DISCUSSION}

Lung worm infection in small ruminants results in huge economic losses as it increases mortality, increases farm inputs via increased treatment expenses and cause reduction in growth rate and possibly weight loss during and after the period of parasitic disease outbreaks. Lung worm infection in small ruminants also exposed animals to many respiratory bacterial and viral diseases of small ruminants. 
In this study, the results showed that the overall prevalence of lung worm infection in small ruminants in the study area was found to be $51.10 \%$ (Table 3). The present finding was closely related with the works of Terefe et al. (2012), Serkalem et al. (2012), Alemu et al. (2006) and Paulos (2000), who were reported the overall prevalence of lung worm infection in small ruminants, $46.00 \%, 55.20 \%$, $53.60 \%$ and $52.40 \%$; in Gondar town, in Dale district, in Northern Ethiopia and in Chilalo respectively. However, the overall prevalence of lung worm infection in small ruminants recorded in this study was much lower than the overall prevalence of lung worm infection in small ruminants that was reported $71.30 \%$ by Sefinew et al., (1999), in Wollo; and it was much higher than the overall prevalence of lung worm infection in small ruminants those were reported $40.40 \%, 29.04 \%, 33.83$ $\%, 26.70 \%$ and $27.60 \%$ by Regassa et al. (2010), Fentahun et al. (2012), Mekonnen et al. (2010) and Dawit and Abdu (2011) and Uqbazghi (1990); in Dessie and Kombolcha districts, in Jimma, in Gondar town and in Hamassin Awraja respectively. Such difference in overall prevalence of lung worm infection might be arise from difference in time of study, duration of study, sample size used, agro - ecologic conditions, management and health care of sheep and goats in the study sites, the sensitivity of the diagnostic methods used to recover the larvae (L1) from fecal samples and adult parasites from lung lesions and the skill of the inspector.

However, the overall prevalence of lung worm infection in small ruminants was different with species of animals; and it was $54.40 \%$ and $32.10 \%$ in sheep and goats respectively (Table 3). The association of the overall prevalence of lung worm infection in small ruminants in relation to species of animals was found to be highly statistically significant $(\mathrm{P}<0.05)$ (Table 7). Similar finding was also reported by Regassa et al. (2009), who reported the overall prevalence of lung worm infection in Dessie and Kombolcha districts, with prevalence of $40.40 \%$ ) and $31.70 \%$ ) in sheep and in goats respectively. Such variation in prevalence of lung worm infection between the two species of small ruminants might be arising from the difference in grazing behavior of the two species of animals. It is known that sheep predominantly grazer so that they have higher exposure to ingest large number of infective larvae (L3) in pasture than goats which mostly browser. Goats with their browsing behavior have less exposure to ingest the infective larvae (L3) that is why the overall prevalence of lung worm infection in goats is lower as compared in sheep.

The specific prevalence of lung worm infection in relation to sex of animals was assessed and analyzed. It was found that the specific prevalence of lung worm infection in small ruminants was different with different sex groups of animals; and it was $52.40 \%$ and $45.50 \%$ in female and male animals respectively (Table 8 ). The association of the overall prevalence of lung worm infection in relation to sex of animals was found to be statistically insignificant $(\mathrm{P}>0.05)$ (Table 11). Similar finding was also reported by Alemu et al. (2006), who reported the prevalence of lung worm infection in Northern Ethiopia, $59.3 \%$ and $44.4 \%$, female and male animals respectively. Similarly, Addis et al. (2010) reported the prevalence of lung worm $36.22 \%$ and $30.43 \%$ in female and male animals respectively in Gondar Town. However; this finding was not agree with the work of Serkalem et al. (2012) in Dale district, who reported the equal susceptibility of the two sex groups for lung worm infection. However, the difference in prevalence of lung worm infection between the two sex groups that was observed in this study might be due to the fact that resistance of female animals to lung infection can be reduced at the time of parturition and during early lactation. Per parturient and lactation relaxation of the resistance of animals may result in female animals to unable to expel adult worms, and cause higher level of larvae detection. This finding was in agreement with those described by Craig (1998). The other reason was the way how males and females were treated in terms of nutrition in the area might also attribute for such difference; because males were kept for fattening to be sold except some which were kept for breeding, thus, males received more attention by farmers than females( Beyene et al., 2013).

The overall prevalence of lung worm infection in relation to the age of animals was also assessed and analyzed. It was found that the prevalence of lung worm infection was different in different age groups of animals; and it was $51.50 \%$ and $47.80 \%$ in adult animals (> 1 year) and in young animals ( $\leq 1$ year) respectively (Table 9$)$. The association of the overall prevalence of lung worm infection in relation to the two age categories of animals found to be statistically insignificant $(\mathrm{P}>0.05)$ (Table 11). However, this finding did not agree with the finding of Fentahun et al. (2012); study conducted in and around Jimma Town, Southwest Ethiopia; who reported the higher prevalence of lung worm infection in young animals $(33.91 \%)$ than adults $(22.73 \%)$. The document described that the reason of higher prevalence of lung worm infection in young animals as compared the adult ones was that 
susceptibility to lungworm infection decreases when age of animals increases. The difference might be due to the proportion of young and adult animals sampled in each study; as this study was conducted in abattoir more numbers of samples were taken from adult animals than young ones.

The prevalence of lung worm infection in relation to body conditions of animals was assessed and analyzed. It was found that the prevalence of lung worm infection in small ruminants was different with different body condition of animals; and it was found $53.90 \%, 50.00 \%$, and $41.70 \%$ in medium, good and poor body condition category of animals respectively (Table 10). The association of the overall prevalence of lung worm infection in relation to the three different body condition categories of animals was statistically insignificant $(\mathrm{P}>0.05)$ (Table 11). This finding was in total agreement with the result reported by Mengestom (2008); study conducted in Tigray (Atsbi). The possible reason for this difference might be due to the fact that animals of good body condition were more nourished animals appeared to be less competent to resist lungworm infection than others. The reason for this could be due to the fact that animals with good body condition are poorly ride off infection although it is usual for well - fed animals provided the right environmental conditions are made available. The result was in agreement with those described by Kimberling (1988). Prevalence of lungworm infection by coprological examination was higher in animals with good body condition $(50.00 \%)$ than animals with poor body condition $(41.70 \%)$ (Table10). Similar finding was reported by Mengestom G (2008); a research conducted in Tigray (Atsbi). The possible reason for this finding might be due to the fact that loss of body weight in small ruminants could not be attributed to lungworm infection alone; since Haemonchuscontortus and other GIT helminthes could be encountered together as mixed infection. So that loss of body weight in small ruminants cannot be attributed only to the lungworm infection alone but it could be due to failure to de worm the animals or else poor body condition could be due to lack of feed or nutritional and management related problems.

In this study, the major species of lung worms of the area were identified coprologically; and it was found that Muellerius capillaris,Dictyocaulus filaria and Protostrongylus rufescens were the major species of lung worms which caused lung worm infection in small ruminants in the area. It was found that mixed infection by two or more species lung worms was also observed. However, the prevalence of different species of lung worms was found to be different; and it was found $19.30 \%(74 / 384)$, $18.20 \%$ (70/384), $4.2 \%(16 / 384)$ and $9.4 \%$ (36/384) of animals were infected by Muellerius capillaris, Dictyocaulus filaria, Protostrongylus rufescens and by mixed infection of two or more species of lung worms respectively (Table 4). In the present study, M. capillaris was found to be the most prevalent species of lung worm in sheep and goats followed by D. filaria and mixed infections; but $P$. rufescens was the least prevalent species in the area. This result totally agrees with the findings of Sisay (1996) who reported that M. capillaris was the highest prevalent species of lung worm in small ruminants; a research work that was done at Bahir Dar. . However, the present result does not agree with the work of Alemu et al. (2006) who reported that D. filaria was the most prevalent species of lung worm in small ruminants; a research work that was conducted inNorth Western Ethiopia. The reason for high prevalence of Muellerius capillaris ascompared with Dictyocaulus filaria in the study area might be partly attributable to its wide range of intermediate host and the ability of larvae to survive in winter in the molluscs. Additional factors which play a part in ensuring the endemicity of Muellerius capillaris are, first, the ability of L1 (first stage larva) to survive for months in faecal pellets and secondly, the persistence of the L3 (third stage larva) in the intermediate host in the life time of the molluscs (Taylor et al., 2007). On the other hand, the longevity and development of free larvae of Dictyocaulusfilaria are known to be dependent on humidity and temperature condition of the environment.

The prevalence of different species of lung worms was different with different species, sex, age groups, and body condition of animals. This study revealed that sheep were found to be more susceptible to lung worm infection caused by both species lungworms than goats. This could be due to the fact that sheep in the study area were grazing in watery and damp areas of arid pastures as compared goats; which are thought to be suitable for survival of the larval stage of the parasite and the intermediate host molluscs. The finding was in total agreement with those described by Taylor et al. (2007). But the prevalence of different species of lung worm was almost similar with different sex groups of animals (Table 8). It was also found that the prevalence of D. filaria was higher in young animals $(50.00 \%)$ than in adults $(33.90 \%)$. However, the prevalence of $M$. capillaris was higher in 
adult animals $(39.67 \%)$ than younger ones $(22.72 \%)$; while the prevalence of Protostrongylus rufescens was found to be higher in young animals $(13.63 \%)$ than adult ones $(7.47 \%)$, (Table 9). This difference might be due to the long period of potency and the apparent inability of the final host to develop acquired immunity, so that adult small ruminants have the heaviest, highest infection and the highest prevalence of the disease. This finding was also in total agreement with those described by Taylor et al. (2007). The study further revealed that the prevalence of different species of lung worms in small ruminants was also different with different body condition of small ruminants. It was found that the highest and the lowest prevalent species of lung worms in poor, medium and in good body condition animals were D. filaria and P. rufescens; M. capillaris and P. rufescens; and D. filaria and $P$. rufescens with prevalence of $60.00 \%$ and $20.00 \% ; 42.02 \%$ and $2.80 \%$; and $36.80 \%$ and 10.50 $\%$ respectively(Table 10). This finding was almost in total agreement with those described by Taylor et al. (2007).

In this study, the prevalence of different species of lung worms was assessed and analyzed. It was found that the prevalence of different species of lung worms was different; and it was found that out of the total positive animals in coprological examination, $18.20 \%, 19.30 \%, 4.20 \%$ and $9.40 \%$ were infected by Dictyocaulus filaria, Muellerius capillaris, Protostrongylus rufescens and by mixed infection respectively (Table 12). The association of the prevalence of different species of lung worms in total examined small ruminants was also assessed; and the difference was statistically highly significant $(\mathrm{P}<0.05)$ (Table 12). Similar situation can be observed in other findings reported by Garomssa et al. (2011) in Ambo town with respective prevalence of Dictyocaulus filaria (47.1\%), Muellerius capillaries (58.8\%) and mixed infection (29.4\%).This could be due to the fact that the parasites have different life cycles, appropriate environmental climatic conditions, and intermediate host.

In addition to coprological examination, post mortem examination of the lungs of small ruminants slaughtered at Asella municipal abattoir in study period were investigated for the presence of adult parasites to determine the prevalence of lung worm infection. It was found that the overall prevalence lung worm infection to be $53.10 \%$ (Table 5). However, the overall prevalence of lung worm infection was different in different species animals; and it was $60.10 \%$ and $31.20 \%$ in sheep and goats respectively (Table 5). The association of the prevalence of lung worm infection determined by post mortem investigation of lungs with different species of small ruminants was assessed and analyzed. The result showed that the association of the prevalence of lung worm infection with two species of small ruminants was also statistically highly significant $(\mathrm{P}<0.05)$ (Table 13). This was in harmony with the work of (Dawit, and Abdu, 2011) who reported 35.76\% in sheep than goat 27.0.8\% in Jimma. This might be the difference in the areas of animals which favors the survival of the larvae of the lung worm or the snail intermediate host in case of Protostrongylus rufescens and Muellerius capillaries because the animal coming for slaughter were from different places and the different sample sizes used. It might also be associated with nutritional status, management practice of the animal, rainfall, humidity and temperature differences in the area where they live.

Finally, the overall prevalence of lung worm infection in small ruminants that was determined by coprological examination for the presence of larvae (L1) in fecal samples was compared with the overall prevalence of lung worm infection determined by post mortem examination of lungs for the presence of adult parasites in the lungs. The result showed that the prevalence of lungworm infection obtained by post mortem examination of lungs was almost similar $(53.10 \%)$ with result obtained by coprological examination $(51.00 \%)$. This slightly difference in prevalence of lung worm infection determined by the two methods might be related to worm nodes of the parasite in Protostronglidae because the worm nodules of the Protostronglidae. In Muellerius capillaris, those larvae which reach the lungs of small ruminant remain in the parenchyma and become encysted in fibrous nodules and because such nodules might not contain adults of both sexes, fertile eggs could not deposited in the air passages. For this reason, the number of larvae in the faeces is often not indicative of the degree of infestation; however, these nodules could be detected during postmortem examination (Radostits et al., 2007). Again as stated in (Fraser, 1992), the prepatent, postpatent phase orhypobiosis might also affect the detection of larvae by faecal examination. The slightly higher infection rate observed on postmortem examination as compared with coprological examination might be related to these worm nodules detected in investigated lungs. The result was in agreement with those described by Schneider (2000). In addition to the above reason it was impossible to detect the parasite of Protostronglidae by fecal examination in pre - patent, post - patent phase or during hypobiosis. Furthermore, egg laying 
adult female parasites might be inhibited by the immune reaction of the host. The result was in total agreement with those described by Hansen and Perry (1994) and (Fraser, 1991).

\section{CONCLUSION}

The study on lung worm infection of small ruminant using coproscopic and postmortem examination in Asella municipal abattoir, south east, Ethiopia revealed high prevalence in the study area. The postmortem examination also implies as the coproscopic examination has limited value in terms of estimating the prevalence of lungworm infection in live small ruminants. Different risk factors were found affecting the prevalence; species, age, sex and body condition were pertinent. The high numbers of lungworm infection in the study area indicates that there were conducive for larval development on grazing pasture and the Intermediate hosts of lungworm. The economic implication of the disease seems very huge; therefore regular strategic deworming with broad spectrum antihelminthic is suggestive of control measure

\section{ACKNOWLEDGMENTS}

The authors acknowledge Jimma University College of Agriculture and Veterinary Medicine for supporting the study

\section{REFERENCES}

Addis, M., Fromsa, A. and Ebuy, Y. (2011): Study on the prevalence of Lungworm Infection in Small Ruminants in Gondar Town, Ethiopia. J. Anim. Vet. Adv., 10:1683-1687.

Alemu S, Gelay E, Ayele G, Zeleke A (2006): Study on small ruminant lungworm in North East Ethiopian. Egyptian J. Vet. Parasitol.14 (2):330-335.

Ayalew, A., Tewodros, D. and Alemayehu, W. (2011): Prevalence and risk factors of intestinal parasites among Dergi school children, North Gondar, Ethiopia. J. Parasitol.Vector Biol.,3:75 81.

Beyene, D., I. Sisay, I. Nigussie, D. Ayana and F. Abunna, (2013). The Prevalence of Lungworms in Naturally Infected Sheep of Ambo District, Oromia Ethiopia. Global Veterinaria, 10(1): 93-98.

Charles, M. H. (2006): Diagnostic Veterinary FaecalExamination.Text Book of Diagnostic Parasitology. $3^{\text {th }}$ ed. Stilous, Elsevier Science, London, $\mathrm{P}_{\mathrm{P}}$ page.

Craig TM (1998): Epidemiology of internal parasites: Effect of climate and host reproductive cycles on parasite survival. Proceedings of the Small Ruminants for the Mixed Animal Practitioner,WesternVeterinary Conference, Las Vegas.

CSA (2013): Agricultural sample survey, 2012/2013 (2005 EC). Report on livestock and livestock characteristics. Statistical Bulletin 57. Addis Ababa, Ethiopia, Pp 3.

Dawit, W. and Abdu, M. (2012): Prevalence of Small Ruminant Lung Worm Infection in Jimma Town. Global Vet., 8:153-159.

Dunn,A. M. (1998): Veterinary Helminthology. $2^{\text {nd }}$ ed. William Heinemann Medicine Books Ltd, London, $\mathrm{P}_{\mathrm{P}:} 203$ - 204.

FAO (2002): Production Year Book. Rome, Italy, 54: 200 - 315.

Fentahun, T., Y. Seifu, M. Chanie and N. Moges, (2012): Prevalence of Lungworm Infection inSmall Ruminants in and Around Jimma Town,Southwest Ethiopia. Global Veterinary, 5: 580-585.

Fraser, C. M. (1992): The Merck Veterinary Manual. A Hand Book of Diagnosis, Therapy and Disease Prevention and Control of Veterinarians. $7^{\text {th }}$ ed. Inc Rahway, NIT, USA, Pp 714 - 717.

Geoffrey, L. (1992): Veterinary Helminthology and Epidemiology. $5^{\text {th }}$ ed. BailliereTindall and Cox, London, $\mathrm{P}_{\mathrm{P}} 27-34$.

Hansen, J. and Perry, B. (1994): The epidemiology, diagnosis and control of helminth parasite of ruminant. ILRAD, Kenya, Pp 83.

ILCA (1990): International Livestock centre for Africa annual report, Addis Ababa, Ethiopia, Pp. 37.

Kimberling, C. V. (1988): Diseases of Sheep. $3^{\text {rd }}$ ed., Lea and Febiger, Philadelphia, USA, Pp 99 101.

Mengestom, G., 2008. Preliminary study on prevalence of ovine lung worm infection in Atsbi, DVM Thesis, Jimma University, Jimma, Ethiopia. 
Paulos, A. (2000): Importance of seasonal dynamics of lung worms infection of small ruminants in Chilalo areas, Arsi Zone. DVM Thesis, Faculty of Veterinary Medicine, AAU, Debrezeit, Ethiopia.

Radostits, O. M., Gay, C. C., Cliff, K. W. H. and Constable, P. D. (2007): Veterinary Medicine. A Text book of the disease of cattle, horses, sheep, pigs and goats, $10^{\text {th }}$ ed. Bailler Tindal, London, Pp 1568 - 1569.

Sefinew, A., Esayas, G., Gelagay, A.and Aschalew, Z. (2006): Study on small ruminant lungworms in northern Ethiopia.Veterinary parasitology 10:1016.

Sisay, A. (1996): Preliminary study on the prevalence of Ovine lungworm infection in and around BahirDar, DVM thesis, Faculty of Veterinary Medicine, Addis Ababa University Debreziet. p.36.

Taylor, M.A., Coop, R.L. \& Wall, R.L. (2007). Veterinary Parasitology. Third edition. Oxford: Blackwell Publishing Ltd.

Thrusfield, M. (2005): Surveys in Veterinary Epidemiology. $3^{\text {rd }}$ ed. Blackwell Science Ltd, Cambridge, USA, $\mathrm{P}_{\mathrm{P}} 178$ - 198.

Torncy, P. M. (1989): Manual of Tropical Veterinary Parasitology.Helminths of Livestock and Poultry in Tropical Africa.The International Technical Center for Agricultural and Rural Cooperation. Pp 81 - 85.

TWRAD (Tiyo Woreda Rural and Agricultural Development)., 2008. Basic data of Tiyo district. Pp.20-29.

Uqbazghi, K. (1990): Preliminary survey on the prevalence of lungworm in small ruminants Hamassin Awraja. DVM Thesis, Faculty of Veterinary Medicine, Addis Ababa University, Debre-Zeit, Ethiopia, pp: 58.

Urquhart, G. M., Armour, J. I., Dunn, A. M. and Jennings, F. W. (1996): Veterinary parasitology. $2^{\text {nd }}$ ed. Black well science Ltd, University of Glasgow, Scotland, Pp 41-42; $59-60$. 